Forging Utopia: Orchestral Music. By John Oliver. Performers: National Arts Centre Orchestra, David Alan Miller, conductor; CBC Radio Orchestra, Mario Bernardi, conductor; Judith Forst, mezzo-soprano; Windsor Symphony Orchestra, John Morris Russell, conductor; CBC Radio Orchestra, Jacques Lacombe, conductor. Toronto: CMC Centrediscs 17612, 2012. 1 compact disc (56:54). Contents: Forging Utopia (13:26) -- Unseen Rain (11:37) -- Face in the Abstract (8:52) -- Raven Steals the Light (22:59). \$13.98

John Oliver's first composition teacher was John Adams at the San Francisco Conservatory of Music. From him, Oliver imbibed a humanistic approach and a realization that to connect with the listener, reference needs to be made to sounds already experienced including quotations from well-known compositions, and stylistic elements from various world musics. In his subsequent compositional studies, Oliver became involved with producing electroacoustic music. In Paris he studied the science of human perception of sound. All of these insights came together in his compositional practice as demonstrated in 1988-89, when Oliver won six major awards for works ranging from chamber to orchestral music as well as the electroacoustic medium. This album brings together four of his orchestral works completed between 1995 and 2007 that exemplify his multi-faceted approach.

Written on the brink of the millennium, Forging Utopia (1998) explores musically what the Canadian philosopher, Mark Kingwell, calls in his book, Dreams of the Millennium, "brink culture." Kingwell explores the anxiety about the apocalypse in the Western tradition from a personal, pop culture, and historical philosophical point of view. Somewhat similarly Oliver reviews trends of the past 300 years in Western music.

Beginning with a flourish of activity based on $\mathrm{F}$, a post-minimalist idiom that is "C majorish" gradually builds up a dense orchestral texture. Two simultaneous quotations suddenly appear as violin and cello solos, identified in the score as being from Mendelssohn's Violin Concerto and Bach's Cello Suite No. 1. Shortly after various instruments present snippets of "God Save the Queen" plus the national anthems of Canada, France, the US, Germany and Spain. Out of this, material featuring some aleatoric writing leads the listener to a section marked "jazzy." Variants of the jazzy and aleatoric materials gradually lead to reminiscences of the opening. The conclusion has Oliver's trademark technique of building up to the highest pitch and then rapidly descending to close on an $\mathrm{F}$ major chord. A tour de force of orchestral writing, this work is a delightful listening experience.

The next selection, Unseen Rain (1995), is a song cycle for mezzo-soprano with orchestra of eight poems by the thirteenth-century Sufi poet, Rumi (Jalal al-Din al-Rumi), in English translation. A delicate and usually transparent layering of orchestral lines supports the imagery 
of these quatrains. Sometimes extended instrumental techniques are explored as well. For example, in the fourth poem, "The Mirror," the textual reference "to hold you like a lute" has at its end a chordal strum from the harp. A little later before the line, "You would rather throw stones," the strings, each section with a different rhythmic pattern, bounce the wood of their bows for the specified pitches. Judith Forst beautifully expresses the mysterious and evocative aspects of these texts.

Face in the Abstract (2007), a commission of the Windsor Symphony Orchestra, has its inspiration in the visual art of Johannes Deutsch and Anselm Keefer. Both artists take the familiar, but present the concept with new associations. Examples would be placing familiar outdoor elements upon a basic indoor scene, or combining the portrayal of a memorial hall with a crematorium. Oliver in this three-movement work follows a similar practice. He uses musical ideas that sound familiar, but after analyzing these sound structures with a computer, builds new harmonies and melodies from them. In this work, the listener can hear references to Stravinsky, but then becomes absorbed in noticing the new aspects that Oliver's approach reveals.

Raven Steals the Light (1999) has its genesis in one of the Haida stories about Raven as told and illustrated by Bill Reid and Robert Bringhurst. Beginning with low strings to describe "inky, allconsuming dark," this musical setting portrays Raven as gradually trying to change this situation through the wind instruments with particular emphasis on the combination of oboe and English horn. Indeed, because the composer cites the story at various points in the score, this work would be an ideal choice for an orchestra wanting to do a multimedia presentation. Obviously Oliver has made a point of listening to and noting characteristics of Haida traditional music. He does not use exact quotation, but manages to successfully suggest the background from which this cultural myth emerged.

The performances on this album consist of recordings of the premieres so there is occasional audience noise in addition to applause at the end of each work. They are all fine performances and hopefully the availability of this disc will encourage orchestras to add these and other works by Oliver to their repertoires.

The CD booklet contains program notes by the composer, his biography, and write-ups about the performers. The conductors are presented in alphabetical order, but who conducts what is not given. That information has to be gleaned from the Canadian Music Centre website.

\section{Elaine Keillor}

Carleton University 